JINOTEP 5 (2) April (2019): 50-56

JINOTEP (Jurnal Inovasi Teknologi Pembelajaran)

Kajian dan Riset Dalam Teknologi Pembelajaran

http://journal2.um.ac.id/index.php/jinotep/index

\title{
INTEGRATED MOBILE LEARNING SYSTEM (IMOLES) SEBAGAI UPAYA MEWUJUDKAN MASYARAKAT PEBELAJAR UNGGUL ERA DIGITAL
}

Ence Surahman

Teknologi Pendidikan, Fakultas Ilmu Pendidikan

Universitas Negeri Malang

\section{Article History \\ Received: March 21, 2019 \\ Accepted: April 25, 2019}

Published: April 30, 2019

\section{Keywords}

Mobile Learning,

Masyarakat Pebelajar, SDM Unggul

\begin{abstract}
The development of information and communication technology (ICT) brings significant changes in various fields of human life including the field of education. Education as the main pillar of the nation in order to build the quality of Indonesian human resources with superior character. Education must be able to adapt to the rapid development of science and technology. The integration of internet technology with smart phones gave birth to people's opportunities for lifelong learning. Mobile learning is one of the trends in the field of adult education technology which is now expected to be able to facilitate the learning needs of all groups. Besides that mobile learning can be a solution to the problem of equity and limited access to education. However, government policies are needed to encourage the development of a mobile learning system. The policy in question is ideally in the form of a system that is managed professionally. Thus mobile learning that is well designed, developed, utilized, managed and evaluated is expected to play a role in building a culture of learning and contributing to the improvement of Indonesia's superior and globally competitive human development index.
\end{abstract}

Corresponding author :

Ence Surahman

Universitas Negeri Malang

Jalan Semarang 5 Malang

E-mail: ence.surahman.fip@um.ac.id
2019 Universitas Negeri Malang p-ISSN 2406-8780 e-ISSN 2654-7953 


\section{PENDAHULUAN}

Sebagai negara berkembang, Indonesia memiliki banyak tantangan dalam mewujudkan cita-citanya sebagai negara yang merdeka, bersatu, berdaulat, adil dan makmur. Salah satu tantangan internal yang paling urgen adalah kualitas sumber daya manusia (SDM) dalam mengelola sumber daya alam (SDA) dan mengembangkan ilmu pengetahuan, teknologi dan budaya baru yang inovatif (Alfindasari, 2014). Kualitas SDM Indonesia sebagai modal utama membangun bangsa dituntut mampu bersaing secara global. Terlebih dewasa ini Indonesia telah memasuki era masyarakat ekonomi asean (MEA) dan masyarakat ekonomi global yang menuntut kompetensi yang kompetitif diberbagai bidang. Dengan demikian proses pendidikan, pengelolaan, pembinaan, pemberdayaan dan pengawasan SDM Indonesia perlu dilakukan secara terarah dan berkelanjutan.

Pendidikan sebagai usaha sadar dan terencana untuk mewujudkan suasana belajar dan proses pembelajaran agar peserta didik secara aktif mengembangkan potensi dirinya untuk memiliki kekuatan spiritual keagamaan, pengendalian diri, kepribadian, kecerdasan, akhlak mulia, serta keterampilan yang diperlukan dirinya, masyarakat, bangsa dan negara (Mendiknas:2003). Pendidikan bertanggungjawab dalam menyiapkan SDM Indonesia berdaya saing dunia. Pendidikan yang berkualitas akan berdampak pada peningkatan bidang ekonomi, sosial, politik, hukum, budaya, seni, kearifan lokal termasuk perkembangan ilmu pengetahuan dan teknologi bangsa Indonsia.

Dalam rangka mewujudkan kualitas proses dan kualitas hasil pendidikan diperlukan penjaminan mutu proses yang akan berdampak pada pencapaian kualitas mutu hasil. Ditengah pesatnya perkembangan internet dan perangkat telfon pintar diseluruh kalangan masyarakat Indonesia mendasari diperlukannya upaya membangun tatanan sistem pembelajaran bergerak yang terpadu (integrated mobile learning system). Sistem yang dibangun bertujuan untuk mendukung proses pendidikan pada jalur pendidikan informal, formal maupun non formal. Tatanan sistem yang dimaksud dapat berupa Integrated Mobile Learning System (IMOLES).

\section{PEMBAHASAN}

Integrated Mobile Learning System (IMOLES)

Temuan teknologi internet dan perkembangan teknologi smartphone melahirkan adopsi inovasi dalam berbagai bidang kehidupan umat manusia, salah satunya muncul istilah pembelajaran bergerak (mobile learning) dalam bidang pendidikan. Mobile learning sebagai sebuah inovasi dalam bidang pembelajaran memungkinkan proses pembelajaran menjadi lebih fleksibel tidak terpaku harus selalu di dalam kelas, laboratorium, dan berorientasi dominan kepada guru (teacher centered), melainkan pembelajaran memungkinkan untuk dilakukan secara mandiri oleh peserta didik (student centered) (Surahman, 2017).

Laura, et al. (2016:1) menjelaskan bahwa peningkatan jumlah pengguna teknologi bergerak (mobile technology) dalam masyarakat merupakan sebuah kenyataan. Pada satu dekade terakhir jumlah pengguna layanan mobile phone di dunia meningkat sangat signifikan. Menurut laporan dari International Telecommunications Unit (ITU:2015) jumlahnya mencapai 7.000 juta pengguna di dunia hingga akhir 2015. Di Eropa ITU memperkirakan penetrasi pengguna mobile phone berkisar $125 \%$ dari jumlah penduduk dan rata-rata kebutuhan internet meningkat $70 \%$ sejak akhir tahun 2014.

Berdasarkan data yang dirilis oleh gs.statcounter.com diketahui bahwa peningkatan pengguna sistem operasi Android pada mobile device dan tablet di Indonesia yang sangat pesat pada 3 tahun terakhir. Dengan peningkatan sebesar $49,86 \%$ yakni dari $18,53 \%$ per agustus 2012 menjadi 68,39\% per-agustus 2015. Hal ini menunjukan bahwa penetrasi smartphone berbasis Android semakin pesat. Hal tersebut didukung oleh fakta dilapangan tempat peneliti merencanakan penelitian, bahwasannya dari 31 responden yang memiliki smartphone, terdapat sebanyak $87,1 \%$ yang menggunakan smartphone berbasis sistem operasi Android, selebihnya simbian dan windows phone masing-masing 3,2\% dan IOS sebesar 6,4\%.

Perkembangan telfon pintar idealnya dapat mendukung proses belajar seseorang. Sharon et al. (2011:11) menjelaskan belajar merupakan pengembangan pengetahuan dan keterampilan atau sikap yang baru ketika seseorang berinteraksi dengan informasi dan lingkungan. Lingkungan belajar diarahkan oleh pendidik dan mencakup fasilitas fisik, suasana 
akademik, serta teknologi pengajaran. Berdasarkan beberapa definisi para pakar di atas, dapat disimpulkan bahwa belajar adalah proses seseorang berinteraksi dengan sebuah lingkungan tertentu baik yang secara sengaja dirancang maupun tidak, dimana setelah proses interaksi tersebut, seseorang akan mengalami perubahan tingkah laku yang terjadi secara permanen. Tingkah laku yang dimaksud baik dalam ranah kognitif, afektif maupun sampai pada ranah psikomotorik. Dalam proses pendidikan yang dimaksud belajar adalah proses seorang peserta didik berinteraksi yang terjadi secara aktif dengan lingkungannya baik lingkungan hidup seperti guru, teman belajar, adik dan kakak tingkat, orang tua, masyarakat dan lingkungan tak hidup seperti buku, media pembelajaran, alam dan lain sebagainya.

Jhon Traxler (2009:13) mengatakan bahwa belum ada definisi mobile learning yang jelas. Hal itu dikarenakan ada beberapa definisi yang memiliki makna yang dekat dengan istilah e-learning. Apabila merujuk pada beberapa istilah yang muncul dalam prosiding konferensi dari MLEARN dan WMTE ditemukan kata-kata seperti pribadi, spontan, oportunistik, informal, meresap, terletak, swasta, konteks-sadar, ukuran yang mini (Jhon, 2009:13). Para ahli lebih banyak mendefinisikan istilah mobile learning dikaitkan pada jenis perangkat yang digunakannya. Perangkat yang dimaksud adalah perangkat yang mendukung proses pembelajaran secara mobile yang memudahkan untuk dibawa dan digunakan di mana saja dan kapan saja. Dengan demikian, dipahami secara umum bahwa yang dimaksud mobile learning adalah pembelajaran yang dapat dilaksanakan dimana saja dan kapan saja.

Mobile learning terdapat kenyamanan dalam pemanfaatan fungsi dan kemudahan media atau alat yang digunakan (fungtionality and mobility). Salah satu karakteristik dari mobile learning ini adalah kemudahan dimana alat dapat dibawa dan digunakan dimana saja, kemudian perlengkapan bersahabat dengan pengguna karena mudah digunakan, selanjutnya harganya murah dan mudah digunakan, serta memiliki kestabilan, sekalipun digunakan sambil berjalan, makan, mengobrol, tidur dan lain sebagainya.

Surahman (2017) menjelaskan mobile learning adalah salah satu alternatif rancangan pembelajaran dengan mengoptimalkan peran dan fungsi dari media berbasis perangkat (device) yang mobile, sehingga pembelajaran dapat dilakukan dimana saja dan kapan saja, secara mandiri. Disamping itu mobile learning merupakan bagian dari pembelajaran elektronik atau electronic learning yang kemudian familiar disebut e-learning dimana e-learning itu sendiri bagian dari pendidikan jarak jauh (distance learning). Hubungan antara mobile learning, electronic learning dan distance learning tergambar seperti bagan berikut (gambar 1):

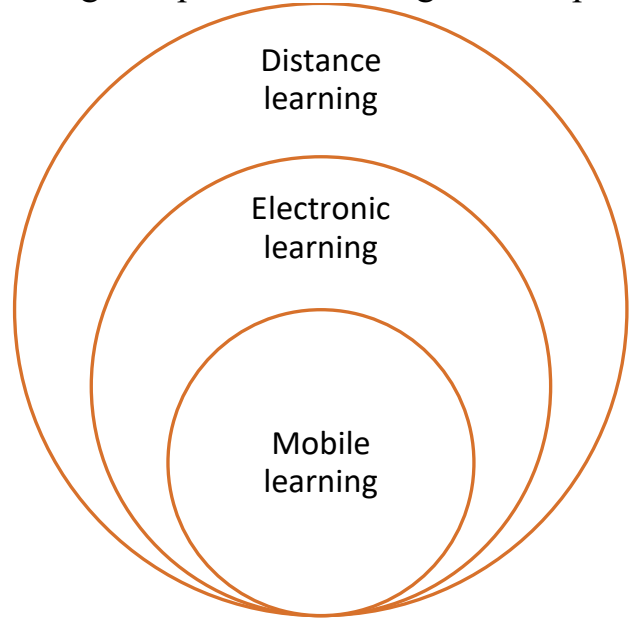

\section{Gambar 1. Bagan Hubungan antara D- Learning, E-Learning dan M-Learning}

Perkembangan teknologi informasi dan komunikasi mendukung pembudayaan belajar sepanjang hayat. Setiap orang dapat terus belajar tanpa harus duduk sebagai pelajar disebuah lembaga pendidikan. Ia dapat mendapatkan input baru berupa pengetahuan dari berbagai sumber baik media elektronik maupun media cetak. Di samping itu perkembangan internet yang pesat memberikan kesempatan lebih luas kepada banyak orang untuk belajar melalui sumber bacaan online dari situs penyedia bahanbahan pembelajaran baik yang bersifat mengikat maupun tidak mengikat. 
Mobile learning merupakan salah satu inovasi yang mendukung kebijakan pendidikan dunia tentang belajar sepanjang hayat. Seseorang dapat belajar tanpa harus menjadi peserta didik disekolah. Ketika ia terhubung dengan koneksi sumber belajar baik online maupun offline maka ia dapat menambah pengetahuan setiap saat ketika ia mau dimanapun dan kapan pun.

Micelle Pieri (Sugiyarto, 2014:4) menjelaskan pembelajaran dengan menggunakan media mobile learning membuat pembelajaran peserta didik menjadi menarik dan menyenangkan. Proses belajar akan efektif apabila peserta didik berada dalam kondisi senang dan bahagia. Begitu juga sebaliknya, peserta didik akan merasa takut, cemas, waswas, merasa tidak nyaman yang dapat mengakibatkan hasil kurang optimal apabila proses belajar peserta didik terlalu dipaksakan (Eko Susanto, 2009: 19-20).

Hal ini sejalan dengan konsep individualize learning atau pembelajaran mandiri. Seorang anak jika diberikan pilihan dalam belajar maka ia akan memilih yang sesuai dengan keinginannya, ada peserta didik yang lebih senang belajar bersama teman-temannya, ada yang memilih berlajar mandiri di perpustakaan, ada yang minta dibimbing belajar di laboratorium, ada yang mendalami materi dari internet, bertanya kepada guru atau langsung observasi ke lapangan. Mobile learning dalam praktiknya memberikan kesempatan bagi peserta didik untuk memilih waktu, tempat dan suasana yang tepat ketika ia mulai merasa butuh untuk belajar. Tidak ada tekanan dan paksaaan harus menyelesaikan pencapaian kompetensi dengan dibimbing dan diarahkan langsung oleh guru. Bahkan jika ia merasa kurang maksimal dalam menyerap informasi dan memahami konsep yang sedang dipelajari, ia dapat menundanya untuk kemudian dilanjutkan pada waktu yang lebih cocok menurut dirinya.

Sutopo (2012:176) menjabarkan beberapa kelebihan mobile learning diantaranya: 1) Convinience yang berarti pengguna dapat mengakses dari mana saja pada konten pembelajaran termasuk kuis, jurnal, games, dan lainnya. 2) Collabboration, yang berarti pembelajaran dapat segera dilakukan setiap saat secara real time. 3) Portability yang berarti penggunaan buku diganti dengan media penyimpanan, sehingga perangkat dapat dibawa dan dioperasikan dimana saja dan kapan saja. 4) Compatibility yang berarti pembelajaran dirancang secara optimal agar dapat digunakan para perangkat mobile (mobile device). 5) Interesting yang berarti pembelajaran yang dikombinasikan dengan game, animasi, quis, video, akan menyenangkan.

Dari beberapa keunggulan mobile learning tersebut di atas, menjelaskan bahwa mobile learning sebagai alternatif layanan pembelajaran masa kini yang adaptif dengan perkembangan ilmu pengetahuan dan teknologi, menawarkan kemudahan, kecepatan, keluwesan, dan kemenarikan tanpa mengurangi esensi dari hakikat dan prinsip pembelajaran secara umum. Keunggulan mobile learning dalam hal waktu dan tempat memberikan kesempatan kepada peserta didik untuk dapat mengakses materi dan informasi kapan pun dan dimana pun (Ally:2009:1). Peserta didik dapat memilih waktu dan tepat yang sesuai dengan kesiapannya untuk belajar, hal ini sejalan dengan prinsip belajar menyenangkan, artinya mobile learning memberikan alternatif waktu dan tempat untuk belajar tanpa adanya tekanan dari pihak eksternal diri peserta didik.

Selain memiliki beberapa kelebihan, Sutopo (2012:176) menjelaskan beberapa kelemahan mobile learning diantaranya. 1) Layar yang sempit pada perangkat mobile, tidak dapat menampilkan informasinya yang banyak, sehingga informasi harus dirancang secara singkat, padat dan jelas. 2) Kapasitas penyimpanan yang terbatas, menyebabkan keterbatasan aplikasi yang dibuat tidak sebesar aplikasi yang dikembangkan dan digunakan pada komputer desktop. 3) Kekuatan battery yang berbatas waktu, hal ini juga menjadi kendala. Battery yang tiba-tiba habis menyebabkan ketidaknyamanan pengguna mobile learning. 4) Keterbatasan sistem operasi menyebabkan suatu aplikasi yang dijalankan pada suatu perangkat belum tentu dapat dijalankan diperngkat yang lain. Bahkan format file dalam komputer juga belum tentu dapat dibuka dalam perangkat mobile. 5) Keterbatasan perangakat keras (hardware) juga memungkinkan tidak mendukungnya suatu perangkat karena tidak memiliki spesifikasi perangkat yang mendukung. 6) Aplikasi yang dijalankan pada perangkat mobile mudah rusak (error, corrupt) dan harus diinstalkan kembali. 7) Keterbatasan untuk dikembangkan pada perangkat mobile secara umum, sehingga pengembangan media mobile learning harus dirancang untuk perangkat mobile tertentu. 8) Perangkat keras mobile terlalu cepat berubah, 9) 
54 JINOTEP (Jurnal Inovasi dan Teknologi Pembelajaran) Kajian dan Riset dalam Teknologi Pembelajaran Vol. 5, No. 2, April 2019, Hal. 50-56

Bandwidth pada nirkabel terbatas dan kemungkinan terjadi penyimpangan dan banyaknya jumlah pengguna yang sedang mengakses. 10) Kesulitan untuk mencetak konten dalam mobile learning.

Beberapa kelemahan dari mobile learning pada dasarnya dapat disiasati agar pengembangannya tidak sia-sia. Salah satu upaya yang dapat dilakukan adalah produk mobile learning yang dikembangkan harus melewati proses analisis kebutuhan dan analisis kelayakan untuk dikembangkan pada satuan pendidikan tertentu. Hal itu bertujuan agar mobile learning yang dikembangkan adaptif dengan karakteristik pengguna, dan didukung oleh sarana dan prasarana yang dimiliki baik perangkat keras maupun perangkat lunak, seperti kepemilikan mobile device, smartphone, tablet, PDA, ketersediaan koneksi internet, paket data, wifi, jaringan komputer dan lain sebagainya.

Mobile learning sebagai multimedia pembelajaran dapat dipahami bahwa produk mobile learning yang dimaksud berfungsi sebagai program multimedia pembelajaran. Multimedia pembelajaran adalah program perantaran materi pembelajaran yang disajikan dalam beberapa format media, seperti teks, gambar, audio, video, dan animasi. Penelitian tentang mobile learning terus meningkat (Koole, 2009:26). Para ahli meyakini bahwa pengembangan mobile learning menawarkan berbagai kemudahan dan kelebihan yang tidak dimiliki oleh pendekatan pembelajaran lainnya.

Koole (2009:25) menjabarkan sebuah kerangka kerja dalam pengembangan mobile learning yakni Framework for the Rational Analysis of Mobile Education (FRAME). Model tersebut menjelaskan bahwa mobile learning merupakan hasil dari proses pemusatan fungsi teknologi mobile, kapasitas belajar manusia, dan interaksi sosial. Ketiga hal tersebut merupakan dasar pedagogis kontemporer dalam pengembangan mobile learning (Surahman, 2017).

Model FRAME menjelaskan keterkaitan antara perangkat (devices), pembelajaran (learners), dan aspek sosial (social). Berikut pada gambar 3 menunjukan bahwa keterkaitan antara perangkat, pembelajar dan sosial yang membangun mobile learning menurut Koole (2009:27).

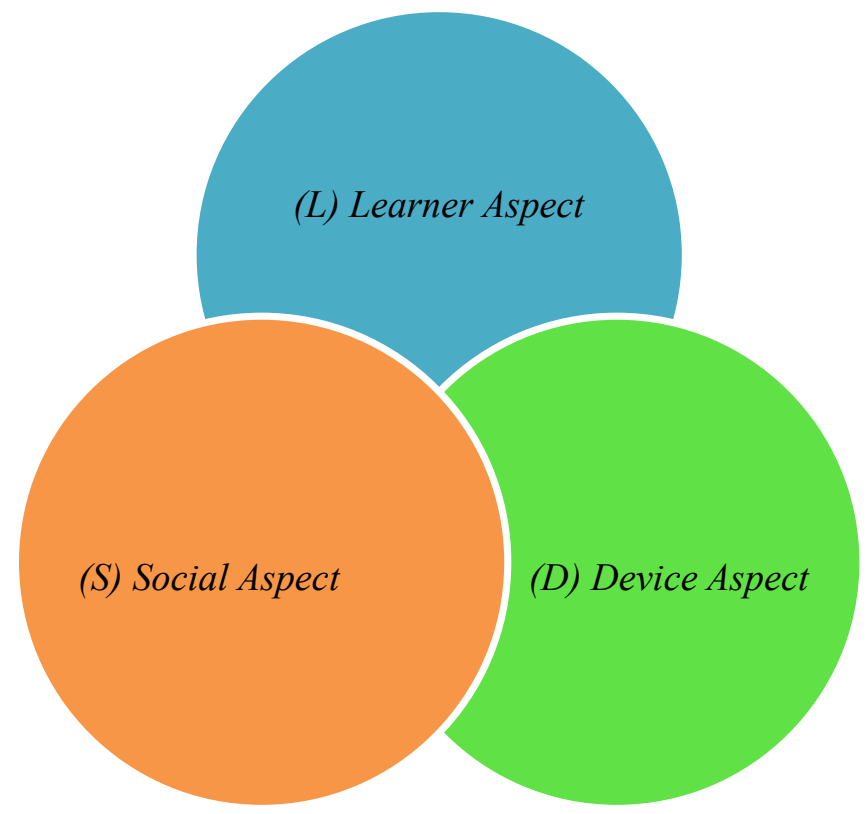

Gambar 2. Bagan Model FRAME (Koole: 2009:27)

Hubungan antara aspek pembelajar dengan aspek sosial melahirkan interaksi pembelajaran. Hubungan antara aspek perangkat dengan aspek sosial melahirkan sosial teknologi. Adapun hubungan antara aspek perangkat dengan aspek pembelajar melahirkan konsep kebermanfaatan perangkat. Hubungan antara aspek perangkat, aspek sosial dan aspek pembelajaran melahirkan mobile learning.

Dalam pengembangan Indonesia Mobile Learning System (IMOLES) diperlukan data center. Pembangunan data center disesuaikan dengan kebutuhan data masingmasing wilayah. Dengan demikian selain data center pusat, diperlukan data center pendukung 
pada tingkat wilayah. Logika sistem data center yang dibutuhkan seperti pada gambar 3 .

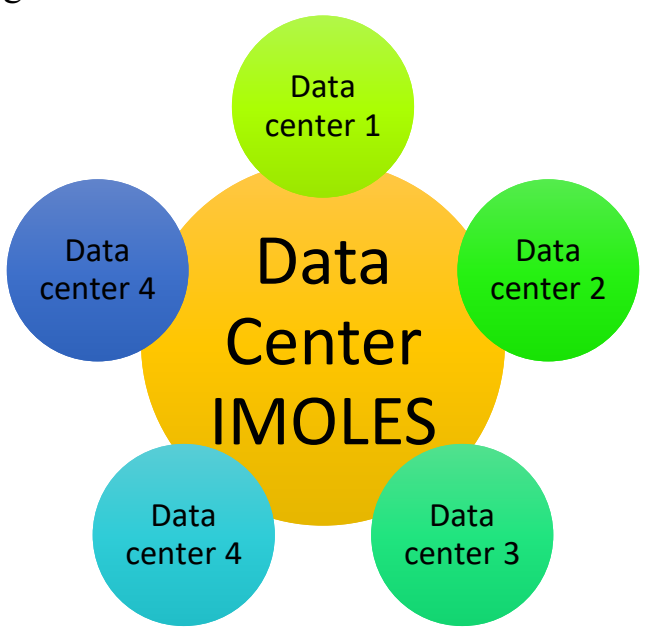

\section{Gambar 3. Bagan Data Center Pusat dan Wilayah IMOLES}

Fokus gagasan yang dikembangkan adalah sistem pembelajaran bergerak yang terpadu secara nasional (Integrated Mobile Learning System) yang dapat diakses pada flatform telfon pintar yang sudah memasyarakat (gs.statcounter.com:2015). Dalam sistem yang dibangun para pengguna dapat memilih alternatif peran baik sebagai pengunjung biasa, peserta didik, pendidik, pengembang konten, pengembang alat evaluasi, pengawas mutu proses dan peran sebagai pendudung keberlangsungan sistem yang dibangun. Secara sederhana gambaran alternatif peran yang dapat diambil sebagaimana gambar 3 .

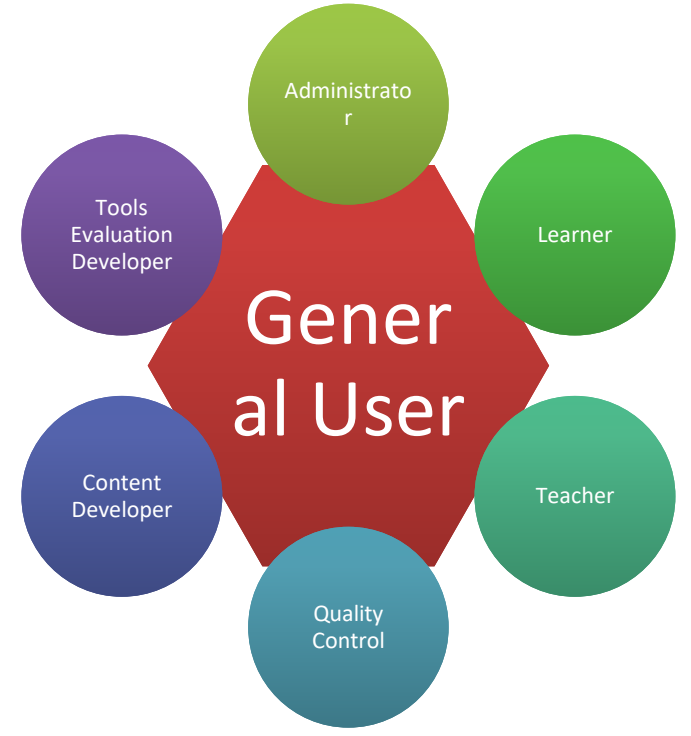

\section{Gambar 3. Alternatif Peran Pengguna IMOLES}

Pembagian peran dikelola secara otomatis pada sistem yang dibangun. Seseorang yang berkunjung pada sistem IMOLES dapat membuka atau mengikuti sebuah kelas yang dibutuhkannya. Proses pembelajaran berjalan secara alamiah pada masing-masing kelas. Proses logikanya seperti pengelolaan banyak jurusan pada sebuah universitas. Masing-masing fakultas memiliki beberapa departemen, dan masing-masing departemen memiliki beberapa program studi, dengan beberapa dosen dan mahasiswa yang belajar pada suatu bidang ilmu tertentu. Di dalamnya terdapat proses registrasi, verifikasi, pembagian kelas, proses pembelajaran, evaluasi dan pemberian keterangan atas pencapaian terhadap kompetensi yang dipersyaratkan. 
56 JINOTEP (Jurnal Inovasi dan Teknologi Pembelajaran) Kajian dan Riset dalam Teknologi Pembelajaran Vol. 5, No. 2, April 2019, Hal. 50-56

\section{SIMPULAN}

Hasil kajian ini diharapkan mampu memberikan kontribusi berupa tatanan sistem pembelajaran bergerak terpadu (integrated mobile learning) secara nasional. Melalui Integrated Mobile Learning System (IMOLES) proses pembelajaran bergerak dapat dikelola secara efektif melalui pengawasan yang baik. Keunggulan yang akan ditawarkan melalui IMOLES adalah kemampuan menyerap para pebelajar (learners) dari semua jalur dan jenjang pendidikan sesuai minat dan kecenderungan kompetensi yang akan dikuasainya. Target makro yang diharapkan melalui sistem yang dibangun adalah terciptanya masyarakat belajar maya (cyber learners). Selain itu Indonesian Mobile Learning System (IMOLES) diharapkan menjadi salah satu alternatif bagi pengguna telfon pintar. Sehingga waktu dan premi paket data yang dibayarkan dapat dikonversi menjadi wawasan dan ilmu pengetahuan baru yang lambat laun diharapkan dapat berkontribusi terhadap peningkatan kualitas SDM Indonesia yang unggul dan berdaya saing global.

\section{DAFTAR PUSTAKA}

Alfindasari, D., \& Surahman, E. (2014). Sumber daya manusia dan pendidikan di era global: sebuah tinjauan terhadap penelitian teknologi pendidikan di LPTK. In Proceeding Seminar Nasional Teknologi Pembelajaran. Yogyakarta: UNY.

Ally, M. (Ed.). (2009). Mobile learning: Transforming the delivery of education and training. Athabasca University Press.

Briz-Ponce, L., Pereira, A., Carvalho, L., JuanesMéndez, J. A., \& García-Peñalvo, F. J. (2017). Learning with mobile technologies-Students' behavior. Computers in Human Behavior, 72, 612-620.

gs.statcounter.com. (2015). Top 8 Mobile \& Tablet Operation System In Indonesia Form Jan to Aug 2015.

Koole, M. L. (2009). A model for framing mobile learning. Mobile learning: Transforming the delivery of education and training, 1(2), 2547.

Pemerintah Republik Indonesia. (1945). UndangUndang Dasar Tahun 1945. Jakarta.

Pemerintah Republik Indonesia. (2003). UndangUndang Republik Indonesia No 20 Tahun 2003 tentang Sistem Pendidikan Nasional. Jakarta.

Rose, C., \& Nicholl, M. J. (2002). Accelerated learning for the 21st century: cara belajar cepat abad XXI. Bandung: Nuansa.

Surahman, E., \& Surjono, H. D. (2017). Pengembangan adaptive mobile learning pada mata pelajaran biologi SMA sebagai upaya mendukung proses blended learning. Jurnal Inovasi Teknologi Pendidikan, 4(1), 26-37.

Surahman, E., \& Alfindasari, D. (2017, September). Developing adaptive mobile learning with the principle of coherence Mayer on biology subjects of high school to support the open and distance education. In 3rd International Conference on Education and Training (ICET 2017) (pp. 184-190). Atlantis Press.

Surahman, E., Wedi, A., Soepriyanto, Y., \& Setyosari, P. (2018, December). Design of Peer Collaborative Authentic Assessment Model Based on Group Project Based Learning to Train Higher Order Thinking Skills of Students. In International Conference on Education and Technology (ICET 2018) (pp. 75-78). Atlantis Press.

Susanto. E., (2009). 60 games untuk mengajar. Yogyakarta: Lukita.

Sutopo, A. H. (2012). Teknologi informasi dan komunikasi dalam pendidikan. Yogyakarta: Graha Ilmu, 131-134.

Traxler, Jhon. (2009). Current state of mobile learning. Canada. AU Press.metacognitive learning approach based on lesson study. International Journal of Education and Research, 3(2), 169-180.

Ziniel, C. E., \& Ghalib, A. K. (2017). Informed Teaching-A Mixed-Methods Approach to Assessing Perception and Practice Within a Higher Education Setting. SAGE Publications Ltd. 